\title{
Sociedade civil e Estado no Brasil: da autonomia à interdependência política
}

\author{
\begin{tabular}{c}
\hline \hline Leonardo Avritzer \\
Departamento de Ciência Política \\
Universidade Federal de Minas Gerais
\end{tabular}
}

Resumo: O conceito de sociedade civil é bastante contestado no seu uso e na sua capacidade de explicação analítica. Reelaborado na teoria democrática nos anos 1990, ele tem sido bastante utilizado no Brasil em diferentes acepções. Alguns autores defendem o seu uso, tal como estabelecido na sociologia-política norte-americana (Cohen e Arato) enquanto outros criticam a ideia da autonomia social a ele inerente. Neste artigo, descrevo o surgimento da sociedade civil no Brasil durante os anos setenta e analiso suas principais áreas de atuação durante sua primeira fase. Analiso também uma segunda fase de interação entre Estado e sociedade civil, mostrando a existência de uma interdependência entre ambos.

Palavras-chave: sociedade civil; autonomia; interdependência; democratização; participação social

Abstract: The concept of civil society is essentially contested in its capacity to explain modern societies. It has been re-elaborated during the early nineties and in its renewed version has been employed in Brazil. A few authors defend its analytical use within the new anglo-saxon model provided by Cohen and Arato whereas other authors criticized the idea of social autonomy. In this article I will describe the emergence of civil society in Brazil during the late seventies and will approach its main area of social action during this first stage. I will also approach a second phase in civil society organization in which it moved to a strategy of interdependency with the state.

Keywords: civil society; autonomy; interdependency; democratization; social participation 
OPINIÃO PÚBLICA, Campinas, vol. 18, n², novembro, 2012, p. 383-398

Sociedade civil foi um conceito relacionado aos países da Europa e aos Estados Unidos até o início da terceira onda de democratização (COHEN \& ARATO,1992; KEANE, 1988a). Tal conceito surgiu no século XIX, por volta de 1820, como uma dimensão dualista capaz de expressar duas mudanças trazidas pela modernidade ocidental: a diferenciação entre as esferas econômica e familiar com a abolição da escravidão, e a diferenciação entre Estado e sociedade causada pela especialização sistêmica do Estado moderno. Nesse contexto, diferenciação social significou que “...o Estado não é o Estado se sempre se funde com a sociedade civil e esta não é sociedade quando é sociedade política ou o Estado" (RIEDEL,1984, p. 133). Assim, em sua primeira formulação, a sociedade civil é um conceito dualista, que expressa o início de um processo de diferenciação entre Estado e sociedade na Europa.

Ao longo do século XIX, o conceito de sociedade civil não pôde ser utilizado para além dos limites dos países do Atlântico Norte porque os processos sociais que expressava pertenciam exclusivamente àqueles. No caso do Brasil, as primeiras diferenciações modernas entre a economia doméstica e a esfera privada não tiveram lugar no mesmo período, com a grande propriedade rural servindo de "locale" para o exercício da dominação econômica e política. O conceito não era aplicável até, pelo menos, o início do século XX a uma situação de pouca diferenciação entre o privado e o público. O Brasil do início do século XIX ainda passava por um processo político privatista (FREYRE, 1959) no qual a grande propriedade rural era o lugar de realização das atividades públicas. Esse processo anterior resultou em uma esfera privada desproporcionalmente grande e a possibilidade sempre aberta de estender as relações pessoais para o campo político. Nenhum processo de diferenciação social que conduzisse a uma ideia de separação entre grandes interesses privados e o Estado poderia ter surgido nesta situação.

O conceito surgiu ou ressurgiu na cena política e social no final do século XX com duas grandes diferenças do seu significado em relação ao século XIX: primeiro, envolvendo um significado tripartite, em que a sociedade civil se diferencia tanto do mercado como do Estado. Assim, diferentemente do início do século XIX, o mercado entendido como a esfera das atividades econômicas privadas também se diferencia da sociedade civil. Em segundo lugar, o conceito de sociedade civil reaparece para explicar os processos sociais que estavam ocorrendo nos países da Europa do Leste e nas sociedades latinoamericanas (ARATO, 1981; COHEN \& ARATO, 1992; KeANE, 1988a; 1988b; 1998; HABERMAS, 1995). O significado tripartite do conceito está ligado à diferenciação do final do século XX entre o mercado e a sociedade e tem recebido diferentes formulações na literatura. Cohen e Arato, em seu trabalho seminal sobre a sociedade civil, diferenciaram a sociedade civil dos "...mecanismos que coordenam a ação na economia (dinheiro) ou em organizações formalmente organizadas e burocraticamente estruturadas (poder)"(COHEN \& ARATO, 1992, p. 429). Eles relacionaram a sociedade civil ao nível institucional de um mundo da vida, entendido como um lugar de socialização, interação social e atividades públicas. Esta é uma das raízes de um modelo tripartite da sociedade civil, que também pode ser identificada em outras tradições do pensamento social, entre elas a diferenciação entre sociedade civil, sociedade política e Estado em Gramsci (BoBBıo, 1988; OxHORN, 1995). Aqueles que defendiam um conceito gramsciano de sociedade civil tentaram concentrar-se mais fortemente na ideia de conflito e na ideia de uma luta pela hegemonia cultural no seio da sociedade civil (FONTANA, 2011). Para eles, o elemento central das sociedades civis latino-americanas deveria ser a tentativa de ir além de uma concepção funcional da 
AVRITZER, L. Sociedade civil e Estado no Brasil: da autonomia à interdependência política

política para se concentrar em disputas de hegemonia no campo da cultura e no território geográfico (OXHORN, 1995). Há ainda uma terceira fonte para o ressurgimento do conceito de sociedade civil, que é uma tradição neo-tocqueviliana ou neo-durkheimiana que diferenciou a esfera do Estado da esfera das associações voluntárias. Nesta concepção, a sociedade civil é uma instância autônoma de produção de solidariedade social (SHILls, 1990; FEINBERG, WAISMAN e ZAMOSC, 2006). Nos três casos, a sociedade civil adquiriu o significado de um conceito cujo ressurgimento foi além dos modelos dualistas do século XIX, de diferenciação do Estado e da sociedade, tanto devido à sua independência da economia de mercado, quanto ao reconhecimento de que o problema da solidariedade social não pode encontrar uma solução satisfatória na esfera privada.

Durante a democratização brasileira, a sociedade civil surgiu como um conceito relacionado à sua nova forma tripartite e expressou a nova concepção de maneira particular: atrelou o surgimento do conceito ao processo de reconstituição dos laços sociais pelos pobres da América Latina (OXHORN, 1995; Alvarez, Dagnino \& Escobar, 1998; Avritzer, 1994) e setores de classe média (Weffort, 1989; Stepan, 1989) em uma situação em que os atores sociais estavam sob a pressão de um regime autoritário. A sociedade civil foi, então, entendida como sendo um conceito capaz de diferenciar os novos atores sociais emergentes tanto do mercado, aqui entendido como os interesses econômicos privados associados ao regime autoritário, como do Estado autoritário. Todos os Estados autoritários latino. americanos, com a exceção do México, buscaram formas antissociais de organização social através da intervenção em sindicatos e associações voluntárias. Assim, o conceito de sociedade civil na América Latina surgiu como um conceito tripartite adaptado às formas de diferenciação entre o mercado, o Estado e a sociedade que se consolidou na região ao longo do século XX.

No entanto, uma importante ressalva permaneceu no uso do conceito com o avanço da democratização no Brasil: as diferentes formas de relação entre a sociedade civil e o Estado (DAGNINo, 2002). Não havia ferramentas conceituais para compreender estas novas situações. Alguns autores argumentaram na direção de um novo corporativismo em que a organização da sociedade civil desempenharia o papel de novas formas de organização da sociedade para ser integrada na estrutura do Estado (REIS, 1995), enquanto outros queriam sublinhar a dimensão neopluralista. Em todos os casos, houve a necessidade de teorizar as novas práticas democráticas desenvolvidas pela sociedade civil brasileira e descobrir as maneiras pelas quais ela interage com o Estado.

Teorias da sociedade civil durante o final dos anos 1980 e início de 1990 trataram as práticas de atores da sociedade civil em termos de autonomia, que, nesse caso, foi entendida em um sentido muito amplo; como autonomia organizacional do Estado ${ }^{1}$ bem como uma esfera independente para a ação do Estado (SADER, 1988; AvRITZER, 1994). Na medida em que postulou essa ideia de autonomia social, o conceito de sociedade civil incorporou uma dimensão do debate internacional, mas também

${ }^{1}$ O Brasil teve um modelo de corporativismo introduzido durante os anos 1930 por Getúlio Vargas, (1930 a 1945 ), no qual o Estado tinha a prerrogativa de intervir nos sindicatos e associações civis. O Ministério do Trabalho poderia remover a seu critério o presidente dos sindicatos. Além disso, todas as associações civis, a fim de serem capazes de atuar, teriam que ser registradas em cartórios, que obedeciam às leis do Estado sobre as formas aceitáveis e não aceitáveis de organização (WEFFORT, 1979). Durante o processo de democratização, a questão da autonomia da sociedade civil bem como sindical emergiu fortemente no espaço público. Os movimentos da sociedade civil e do sindicalismo reivindicaram autonomia em relação ao Estado (KECK, 1989 ). 
OPINIÃO PÚBLICA, Campinas, vol. 18, n², novembro, 2012, p. 383-398

envolveu fortes elementos locais. Ele incorporou todos os tipos de movimentos sociais na dimensão autônoma da sociedade civil e, até mesmo, uma ideia geral de autonomia que vinha do próprio sindicalismo ${ }^{2}$. Esta dimensão de autonomia mostrou-se muito forte durante o autoritarismo e influenciou um conjunto de movimentos, entre os quais cabe destacar o associativismo comunitário, o movimento de saúde, o movimento da reforma urbana e quase todos os movimentos com a presença de ativistas da igreja católica. Mas a verdade é que este movimento pela autonomia social não sobreviveu à democracia com a mesma concepção com que surgiu.

Uma segunda fase tanto da prática democrática quanto da teoria da sociedade civil surgiu em meados dos anos noventa do século XX e colocou a questão da interdependência entre a sociedade civil e - Estado. No caso brasileiro, a interdependência foi motivada pela sua associação com o aprofundamento democrático (DAgnino, OLVERA \& PANFICHI, 2006). Os atores da sociedade civil superaram uma fase de demarcação de espaço com o Estado e começaram a interagir em conselhos de políticas (TATAGIBA, 2002; 2004) bem como em projetos específicos que envolvem a implementação de políticas públicas (ABERS \& KECK, 2006; AVRITZER, 2008). Neste artigo, descrevo o surgimento da sociedade civil no Brasil durante os anos setenta e analiso suas principais áreas de atuação durante sua primeira fase. Analiso também uma segunda fase de interação entre Estado e sociedade mostrando que a sociedade civil ainda é semiautônoma (CORNWALl \& COELHO, 2007), ou seja, interage com o Estado mantendo a sua própria dinâmica organizacional e o seu próprio processo de tomada de decisão. $\mathrm{Na}$ última parte do artigo, proponho um modelo analítico para analisar a sociedade civil brasileira.

\section{Sociedade Civil no Brasil: explicando a emergência do conceito e a prática dos atores sociais}

A emergência da sociedade civil no Brasil foi uma consequência de vários processos: a forma antissocial adotada pelo autoritarismo brasileiro, que, ao mover a população pobre do campo para as cidades, interferiu nos processos societários mais básicos (SANTOS, 1987; CALDEIRA, 2000). O país passou por um dos processos de urbanização mais rápidos da história, sendo em grande parte um país rural na década de 1940 e passando a ter mais de $80 \%$ de sua população vivendo em cidades no final do século XX (SANTOS, 1987). No processo de deslocamento do campo para a cidade, a população de baixa renda foi despojada de direitos e alocada nas grandes capitais em lugares com pouco ou sem nenhum tipo de serviço público. A organização dos pobres brasileiros para lutar por serviços públicos é uma das origens da sociedade civil brasileira.

Uma segunda razão que levou à emergência da sociedade civil no Brasil é a característica do processo de modernização econômica do Brasil, que transformou as políticas de planejamento urbano, saúde e educação em questões tecnocráticas (ESCOREL, 1998). O regime autoritário brasileiro assumiu uma visão tecnocrática de desenvolvimento urbano e políticas públicas, e tentou integrar os atores de classe média em seu projeto top-down de modernização. Contudo, os atores de classe média reagiram a esse projeto e organizaram formas de ação coletiva e associações para disputar esses elementos

\footnotetext{
2 Vale a pena lembrar que a maior parte da literatura sobre sociedade civil excluía as ações do movimento sindical da categoria sociedade civil. No entanto, no caso brasileiro, a ideia de autonomia adquiriu contornos próprios e houve um trânsito claro entre sindicalismo e associativismo civil. Vide Keck (1989).
} 
AVRITZER, L. Sociedade civil e Estado no Brasil: da autonomia à interdependência política

tecnocráticos. Economistas, médicos, advogados, professores universitários estavam entre os principais atores do processo de reorganização da sociedade civil brasileira (BosCHI, 1987; AVRITZER, 2002).

Uma terceira razão que levou à reorganização da sociedade civil brasileira foi a oposição dos setores liberais e de classe média à ausência de regras e accountability nos processos políticos e civis, que transformou a Ordem dos Advogados do Brasil (OAB) em um dos principais grupos de oposição ao autoritarismo. Embora essas características estivessem presentes durante todo o período da democratização (1977 a 1988, quando a nova Constituição foi promulgada), elas interagiram com dois outros fatores que fizeram a sociedade civil mais ou menos autônoma vis-à-vis o Estado: o aprofundamento democrático que teve lugar durante e após o processo de elaboração da Constituição, e a forma como as reformas neoliberais interagiram com as responsabilidades dos atores da sociedade civil nas políticas públicas. É a partir do resultado dessa interação que diferentes padrões de relações entre Estado e sociedade civil surgiram.

A sociedade civil brasileira ressurgiu durante o processo chamado de "liberalização" que começou durante meados dos anos setenta (O'DONNELL \& SCHMITTER, 1986), momento em que o regime autoritário brasileiro liberou o controle em relação a algumas proibições de reuniões públicas de associações voluntárias, mas não sobre as regras de competição política (STEPAN, 1989). Assim, estudantes puderam reconstituir seu movimento, muitas categorias profissionais como arquitetos, engenheiros e advogados passaram a se reunir de novo e a reorganizar suas associações, muitos sindicatos começaram a ser dirigidos pela oposição e o Ministério do Trabalho não ousou intervir. Foi como resultado deste processo que muitas formas de organização da sociedade civil surgiram: (1) a organização dos movimentos populares dos pobres urbanos em nível local (GAY, 1994; GoHN, 1991); (2) a organização do movimento sanitarista por um Sistema Único de Saúde (ESCOREL, 1998); (3) O movimento para uma Reforma Urbana Nacional (SAULE JúNIOR, 2005); (4) A organização de membros de associações profissionais, como advogados, médicos, professores universitários, entre outros e (5) o desenvolvimento de muitas formas de organização no campo brasileiro, incluindo o surgimento do MST (NAVARRO, 2002). Estes não são todos os movimentos que surgiram ao longo deste período. Movimentos feministas (AlvAREZ, 1990) e movimentos negros também surgiram nessa mesma época, ainda que inicialmente não tivessem tanta influência como os movimentos apontados anteriormente.

O processo de democratização e organização de muitas formas de ação coletiva que teve lugar entre 1974 e 1985 levou a mudanças impressionantes no padrão de associação do país (SANTOS, 1993; GAY, 1994; AVRITZER, 1994; 2000; 2004; BAIOCCHI, 2005). A democratização produziu um aumento significativo na propensão para criar formas voluntárias e independentes de associação. Boschi (1987) demonstrou que mais associações voluntárias foram criadas no Rio de Janeiro entre 1978 e 1980 do que durante todo o período democrático anterior. Santos (1993) demonstrou um fenômeno semelhante para todas as categorias de associações voluntárias nas maiores cidades do país. A Tabela 1 mostra o aumento no número de associações voluntárias criadas em São Paulo, Rio de Janeiro, e Belo Horizonte durante a longa transição do Brasil para a democracia: 
OPINIÃO PÚBLICA, Campinas, vol. 18, n², novembro, 2012, p. 383-398

Tabela 1

Número de associações criadas em grandes cidades brasileiras (1930-1990) ${ }^{3}$

\begin{tabular}{|l|l|l|l|l|l|}
\hline & \multirow{2}{*}{$1941 \cdot 1950$} & $1951 \cdot 1960$ & $1961 \cdot 1970$ & $1971 \cdot 1980$ & \multirow{2}{*}{$1981 \cdot 1990$} \\
\cline { 1 - 5 } Cidade & 288 & 464 & 996 & 1871 & 2553 \\
\hline São Paulo & 188 & 743 & 1093 & 1233 & 2498 \\
\hline Rio de Janeiro & 120 & 204 & 459 & 584 & 1597 \\
\hline Belo Horizonte & - & - & - & 240 & 380 \\
\hline Porto Alegre & & & & \\
\hline
\end{tabular}

Fontes: Santos, 1993; Avritzer, 2000; Baiocchi, 2005.

Vale a pena chamar a atenção para vários aspectos deste fenômeno: o número total de associações dobrou em São Paulo nos anos 1970 e triplicou em Belo Horizonte na década de 1980. 0 aumento foi menor no Rio de Janeiro do que nas outras duas cidades, porque, por razões históricas e políticas, já tinha a maioria das associações voluntárias. Também é importante notar que tem havido não só um aumento quantitativo na vida associativa brasileira (em Belo Horizonte e São Paulo o ritmo de aumento de associações é quase o dobro do crescimento da população no mesmo período), mas também uma mudança qualitativa. Algumas formas de associação voluntária, que não eram muito fortes antes de meados dos anos setenta, cresceram em número e influência: Em Porto Alegre, entre 1986 e 1990, o número de associações de bairro cresceu mais de 50\% - de 240 para 380 (BAIOcCHI, 2005). Os aumentos nas cidades de São Paulo e do Rio de Janeiro também foram impressionantes: das associações de moradores das duas cidades, 97,6 \% e 90,7\%, respectivamente, foram criadas depois de 1970. Outros tipos de associação também foram relativamente novas em todas as três cidades: $92,5 \%$ das associações dos profissionais de saúde em São Paulo foram criadas depois de 1970, assim como $76 \%$ das associações dos advogados no Rio de Janeiro (SANTOS, 1993). Em Belo Horizonte, todas as 29 associações que lidam com meio ambiente, direitos humanos e questões étnicas foram criadas durante esse período. Assim, é possível falar que, em todas as quatro cidades, houve uma mudança muito impressionante no padrão de associação, um processo que envolveu uma propensão crescente para associar-se; um número maior de associações; novas associações para reivindicar benefícios materiais como melhoria da comunidade; e o surgimento de associações lidando com reivindicações pós-materiais, tais como proteção ambiental e direitos humanos.

A mudança no padrão de associação no Brasil está de acordo tanto com os argumentos de densidade (PUTNAM, 1993) como de igualdade (COHEN \& ROGERS, 1995) que têm prevalecido na literatura sobre os efeitos das associações voluntárias na sociedade como um todo. O rápido crescimento no número de associações mostra que as associações voluntárias não são somente ligadas ao processo de formação histórica do país, como Almond e Verba (1963), e até mesmo Putnam, afirmam, mas podem

\footnotetext{
${ }^{3}$ É importante ressaltar que o crescimento foi significativo se comparado com o aumento da população nas três cidades no mesmo período. A população de São Paulo aumentou 43\% entre 1970 e 1980 e 13,5\% entre 1980 e 1990. Contudo, o número de associações na cidade dobrou neste período. O diferencial entre o crescimento de associações e crescimento da população durante todo o período foi de $36,45 \%$. Dados para o Rio de Janeiro e Belo Horizonte são ainda mais convincentes.
} 
AVRITZER, L. Sociedade civil e Estado no Brasil: da autonomia à interdependência política

mudar de forma relativamente rápida em resposta a circunstâncias políticas. No Brasil, o gatilho para essa mudança foi uma experiência autoritária em que o Estado interveio profundamente na vida cotidiana dos pobres através da remoção das favelas das áreas centrais das cidades brasileiras e incentivou uma migração em massa dos habitantes do campo para as cidades, sem fornecer-Ihes saúde, educação e infraestrutura adequadas. Esse fenômeno mostra também o lado igualitário do processo de formação de associações voluntárias (COHEN \& ROGERS, 1995, p. 43). Embora as associações voluntárias no Brasil tenham crescido de modo geral, as que mais cresceram foram aquelas que lidavam com a inserção dos pobres na política. Os pobres organizaram-se no Brasil a fim de reivindicar o acesso a bens públicos distribuídos de forma desigual nas cidades brasileiras. Acesso à saúde, educação, água tratada e esgoto eram muito baixos em todas as regiões do país ao fim do autoritarismo (SANTOS, 1987). A organização dos pobres em associações voluntárias desempenhou, desse modo, o papel de criar uma nova força que poderia influenciar o processo de distribuição de bens públicos.

A principal característica da sociedade civil brasileira durante este primeiro período foi a reivindicação de autonomia em relação ao Estado e aos partidos políticos. A história do Brasil dos anos 1930 à década de 1980 foi de forte intervenção do Estado na organização da sociedade como demonstrado anteriormente. Durante a democratização, a reivindicação de autonomia tinha dois significados principais:

Autonomia organizacional em relação ao Estado. Do trabalho a todas as outras formas de organização dos pobres, a autonomia foi reivindicada pelos atores sociais no período de 1977 a 1985 . Autonomia foi entendida como agir sem pedir autorização do Estado e, ao mesmo tempo, ignorar os limites colocados pelo Estado à organização interna e externa das associações voluntárias. Isso significou que novas associações voluntárias emergiriam e novas formas de apresentar reclamações em público para o Estado tornar-se-iam práticas comuns. Foi neste período que práticas comuns, que podemos chamar de um repertório democrático de ação coletiva pelas associações voluntárias brasileiras, surgiram. Práticas tais como organização de abaixo-assinados, convocação de autoridades estatais, demonstrações em frente a edifícios públicos e organização de assembleias de base surgiram neste período.

A autonomia significou também a tentativa de propor formas de administração de políticas sem a participação do Estado. Assim, o movimento sanitarista de São Paulo durante a primeira metade da década de 1980 propôs uma forma de organização das políticas de saúde independente do Estado. Por mais difícil que seja visualizar como seria a organização desta política pública, o fato de a proposta existir expressa bem o assim chamado "espírito da época". Ainda durante a VIII Conferência Nacional de Saúde, realizada em 1986, havia grupos propondo a organização de serviços de saúde independentemente do Estado (SADER, 1988; AVRITZER, 2008). O movimento pela reforma urbana, de modo semelhante, propôs formas de democracia local, que seriam capazes de vetar a ação do Estado relacionada às políticas urbanas (SILVA, 1990). A UAMPA, criada em Porto Alegre durante a primeira metade dos anos 1980, propôs no seu segundo congresso a tomada de decisões sobre questões de orçamento baseadas em um conselho de associações de bairro. Estes são alguns exemplos da força da ideia de autonomia nos movimentos sociais brasileiros na primeira metade dos anos 1980 . 
OPINIÃO PÚBLICA, Campinas, vol. 18, n², novembro, 2012, p. 383-398

Assim, durante a primeira fase de organização da sociedade civil, podemos notar dois fenômenos: o crescimento quantitativo do número de associações voluntárias lidando com a organização dos pobres e a participação de seus atores na implementação de políticas públicas. Este argumento, que vale tanto para o início da democratização quanto para a sua fase posterior (AVRITZER, 2004), expressa uma nova correlação de forças entre a sociedade civil e o Estado no Brasil. O segundo fenômeno envolve a ideia de que a sociedade civil pode lidar com políticas públicas de forma independente do Estado. Esta foi a concepção de movimentos importantes, como o movimento da saúde/sanitarista e o movimento de reforma urbana. Os dois movimentos radicalizaram a ideia da autonomia social e tiveram forte influência neste período. No entanto, existe um divisor de águas entre a reivindicação de autonomia do Estado nesta primeira fase (1977-1985) e a reivindicação de autonomia durante a segunda fase (1985 até hoje): a Assembleia Nacional Constituinte e o engajamento dos atores da sociedade civil em uma nova fase, que eu chamo de "aprofundamento democrático". Ela redefiniu profundamente a ação da sociedade civil e gerou um novo conceito de autonomia.

\section{A Sociedade civil e o Estado no pós Assembleia Constituinte: a criação de interdependência política}

O período entre 1985 e 1988 foi um divisor de águas na política brasileira, com a convocação da Assembleia Nacional Constituinte (ANC) e a elaboração da nova Constituição. Uma notável característica da ANC adquiriu importância com o tempo, a sua orientação participativa. A ANC permitiu emendas populares e desencadeou uma campanha popular para obtenção de assinaturas para muitas propostas ligadas às políticas públicas. Alguns entre os mais importantes movimentos da sociedade civil, tais como a saúde e os movimentos de reforma urbana, da mesma forma que outros importantes atores sociais, como a CUT (Central Única de Trabalhadores) e o MST (Movimento dos Trabalhadores Sem Terra), também se juntaram à campanha para emendas populares (WHITAKER, 1994). Este foi um primeiro momento de um processo de aprofundamento democrático que criou instituições participativas nas áreas de saúde, planejamento urbano, meio ambiente e assistência social. Uma emenda popular na área da saúde foi apresentada com pouco menos de 60 mil assinaturas (RodRigues Neto, 2003). Seus principais elementos foram: obrigar o Estado a ser o principal provedor de saúde no Brasil; a criação de um sistema de saúde nacional unificado, sem precondições para o acesso; a descentralização da prestação de serviços de saúde; a promoção da ampla participação popular na elaboração e implementação de serviços de saúde (PEREIRA, 1996, p. 446). Apesar da inserção tardia da subcontratação para o setor privado, o movimento de saúde foi muito bem sucedido dentro da Assembleia Constituinte. O artigo 198 da Constituição descreveu a saúde como um sistema integrado organizado de acordo com os seguintes princípios: (1) descentralização; (2) cuidado unificado com foco na prevenção; e (3) participação da sociedade civil nas deliberações de políticas. No entanto, a Constituição exigia a elaboração de uma lei orgânica da saúde para especificar melhor as formas de participação exigidas no artigo 198.

Após quase dois anos da promulgação da Constituição de 1988, a Lei Orgânica da Saúde (LOS) foi vetada pelo Presidente Collor, criando um impasse com o Congresso e protestos no país. A lei 8.080 pretendia instituir um sistema de saúde unificado com ampla participação política, destacando os artigos sobre a participação para veto (ZAULI \& RODRIGUES, 2002). Com a lei 8.142, de dezembro do 
mesmo ano, resolveu-se o impasse, regulamentando a participação no sistema de saúde através da criação de duas figuras institucionais, quais sejam, as conferências de saúde e os conselhos de saúde. De acordo com a lei, conselhos de saúde serão instituições deliberativas permanentes compostas por representantes do Estado, prestadores de serviços e representantes da população que atuariam na elaboração de estratégias, bem como no controle da execução das políticas de saúde em cada um dos níveis de governo (BRASIL, 1990). No rescaldo da aprovação desta lei, muitas cidades brasileiras promulgaram leis locais, todas prevendo a organização de conselhos de saúde baseadas na paridade entre sociedade civil e Estado. Atualmente, existem no Brasil mais de 5.000 conselhos de saúde.

De forma semelhante, o MNRU também fez uma proposta de emenda popular na área de política urbana. A emenda popular sobre a reforma urbana foi apresentada à Assembleia Nacional Constituinte com 131 mil assinaturas e desencadeou uma batalha de lobby com os interesses de imobiliários conservadores. O Comitê Temático sobre Questões Urbanas e Transporte, inicialmente, não atraiu muitos Constituintes influentes, já que setores conservadores tinham questões mais prementes em curto prazo (ARTURI, 2001). Os interesses de imobiliários no interior da Assembleia Constituinte procuraram transferir a decisão final sobre as questões urbanas para outra arena, fora do processo de elaboração constitucional, a fim de evitar a aplicação automática de qualquer nova legislação (SAULE JúNIOR, 1995, p. 28). As propostas da subcomissão sobre questões urbanas permaneceram intactas, em sua maioria, mas estavam integradas com a exigência de que as cidades deveriam ter "Planos Diretores"4, uma proposta feita pelo "Centrão", um grupo informal de parlamentares que reuniu interesses conservadores na Assembleia Constituinte. Assim, o $\S 1^{\circ}$ do artigo 182 da Constituição de 1988 exigiu a participação de organizações da sociedade civil na tomada de decisões sobre questões urbanas e um "plano diretor da cidade aprovado pela Câmara Municipal como obrigatório para todas as cidades com mais de 20.000 habitantes..." (BRASIL, 1988). Todas as propostas de reforma urbana foram condicionadas ao cumprimento desta cláusula, e a consequência da subordinação da agenda de reforma urbana a planos diretores foi a exigência de um estatuto ou um processo infraconstitucional de especificação da constituição. Após uma batalha legal de 13 anos no Congresso, desde a proposta de legislação pelo Senador Pompeu de Sousa, o chamado "Estatuto da Cidade" foi aprovado em 20015 . A obrigatoriedade de planos diretores com audiências públicas define a presença de associações da sociedade civil levando a que centenas de cidades brasileiras tenham planos diretores em que os atores civis e o Estado interagem de perto. Hoje, existem perto de 1500 cidades brasileiras com planos diretores municipais.

Ao mesmo tempo em que a participação nas áreas de saúde e planos diretores municipais desencadearam uma forma intensa de participação com base em associações da sociedade civil, o orçamento participativo também estava em ascensão. Em Porto Alegre, Olívio Dutra o introduziu quando

${ }^{4}$ Os planos diretores da cidade não são dispositivos conservadores per se, embora tenham sido considerados conservadores pelo movimento da reforma urbana devido à maneira como surgiram durante a Assembleia Constituinte. Algumas cidades brasileiras como Porto Alegre têm planos diretores desde o final dos anos setenta. A novidade introduzida pela Assembleia Constituinte foi a exigência de vínculo entre ter um plano diretor e ser capaz de introduzir os outros dispositivos aprovados pela Constituição em seu capítulo sobre a cidade. Ver Avritzer (2008).

${ }^{5}$ Há um caso muito interessante de cancelamento do plano diretor da cidade de Salvador (Bahia), devido à violação da exigência de audiência pública durante a prefeitura de Imbassay. A cidade de Salvador convocou apenas uma audiência pública durante a preparação do seu plano diretor. A audiência pública não foi amplamente divulgada e o Ministério Público Brasileiro pediu seu cancelamento, que foi concedido por um tribunal de Salvador (AVRITZER, 2008). 
OPINIÃO PÚBLICA, Campinas, vol. 18, n², novembro, 2012, p. 383-398

eleito prefeito em 1988. O Orçamento Participativo (OP) é uma política participativa que gera um processo de deliberação entre sociedade civil e Estado no nível local. Ele inclui atores sociais, membros de associações de bairro e cidadãos comuns em um processo de negociação e deliberação que acontece em duas etapas: uma etapa participativa, em que a participação é direta, e uma etapa representativa, na qual a participação ocorre através da eleição de delegados e/ou conselheiros. O OP em Porto Alegre, de 1990 a 2004, envolveu duas rodadas de assembleias regionais, uma rodada de reuniões intermediárias e o funcionamento de um corpo de representantes chamado de Conselho do OP durante o ano todo. A participação nessas reuniões é individual, mas, durante o processo de registro, indivíduos são solicitados a demonstrar participação em associações voluntárias. Além disso, as regiões de Porto Alegre que tiveram níveis mais altos de participação ao longo do processo de implementação do orçamento participativo (1990-1992) foram as que tinham o maior número de associações de bairro (WAMPLER \& AVRITZER, 2004). Processo semelhante ocorre em Belo Horizonte e Recife, cidades com orçamentos participativos e com incentivos para a participação dos delegados em associações da sociedade civil, exemplificando uma forte interação entre a presença de associativismo e a operação de um processo participativo por parte do Estado.

Com a consolidação do orçamento participativo em Porto Alegre, Belo Horizonte, Recife, Ipatinga, Belém, entre outras cidades, muitos líderes de associações de bairro começaram a participar mais intensamente do sistema político local, seja em gabinetes de vereadores ligados ao Partido dos Trabalhadores, seja em entidades com maior expressão político partidária. Nota-se, dessa forma, uma forte mudança no foco da participação de meados dos anos oitenta a meados dos anos noventa do século XX. Durante a primeira metade dos anos oitenta no Brasil, a sociedade civil estava preocupada com a autonomia, a democratização das políticas públicas e o estabelecimento de formas de controle público sobre o Estado, preocupações que inspiraram o marco analítico que pensou a questão da autonomia. Este marco recebeu um conjunto de críticas de natureza mais analítica (LAVALLE, 2004), mas o grande vetor de mudança foi, de fato, uma realidade prático-política que inspirou novos trabalhos sobre o tema. A partir de meados dos anos noventa, a sociedade civil brasileira começou a se preocupar com o estabelecimento de uma forma mais ampla de participação pública na maioria das áreas de políticas públicas (DAGNINO, 2002). Com o forte trabalho de extensão da participação de organizações da sociedade civil no interior do Estado nas áreas de políticas públicas, a questão colocada foi como tais associações/atores poderiam manter a sua autonomia em relação ao Estado.

Há duas questões-chave a serem compreendidas no processo de transformação organizacional da sociedade civil brasileira6: a primeira é que o seu crescimento e da sua influência política seguiram

\footnotetext{
${ }^{6}$ Houtzager, Lavalle e Charia compreenderam mal as características mais importantes desta mudança de perspectiva pelos atores da sociedade civil. Segundo os autores, "a leitura dicotômica das relações Estado-sociedade, surgida nas lutas contra os vários tipos de regimes autoritários na segunda metade da década de 1970 e 1980 , tem sido fundamental para a literatura sobre a sociedade civil e infelizmente tem sido reforçada recentemente... Ainda que as discussões sobre a sociedade civil tenham abandonado as primeiras interpretações de oposição do Estado e sociedade a fim de abordar uma série de temas emergentes . cidadania, novos espaços de participação, desenvolvimento local, governança e prestação de contas/responsividade - a interpretação dicotômica de relações Estado-sociedade tem sido amplamente reproduzida, ainda que de formas mais sutis $A$ metáfora sugere agentes autônomos que se cruzam, descobrem certos interesses sobrepostos e escolhem se envolver com o outro através de vários mecanismos institucionais" (HoutZAGER, LAVALLE \& CHARIA, 2004, p.312.313). Em contraste com o argumento dos autores, toda a literatura recente sobre a sociedade civil enfatiza as interconexões entre a sociedade civil e o Estado. A razão é muito simples: o modelo de autonomia plena estava ligado à concepção dos atores sociais e não a uma
} 392 
uma lógica mista entre autonomia e dependência. Em uma pesquisa sobre o comportamento de atores associados aplicada em São Paulo em 2004, esta mistura de características no perfil de participação foi observada. Perguntamos a 2.043 pessoas de uma amostra aleatória de toda a cidade se elas participavam de associações da sociedade civil e se costumavam participar, sem no momento serem membros de qualquer associação da sociedade 7 . A Tabela 2 mostra os resultados:

Tabela 2

Participação em associações (\%)

São Paulo, 2004

\begin{tabular}{|l|l|l|}
\hline Tipo de associação & Participa & $\begin{array}{l}\text { Participava mas não é neste momento um } \\
\text { membro de qualquer OSC }\end{array}$ \\
\hline Associações de bairro & 2.0 & 6 \\
\hline Associações de Saúde & 0.7 & 2 \\
\hline Movimento de moradia & 1.0 & 3 \\
\hline Associações religiosas & 9.0 & 8 \\
\hline
\end{tabular}

Fonte: Avritzer, 2004.

Os dados sugerem para São Paulo um fenômeno muito interessante. Devido à implementação da participação por duas administrações do PT, em 1988 e em 2000, e sua posterior descontinuação por administrações conservadoras, os dados mostram que as associações da sociedade civil têm um núcleo composto de formas religiosas de participação pública que têm uma lógica autônoma vis-à-vis as políticas do Estado ${ }^{8}$. Esta lógica autônoma é mais bem expressa no número constante de participantes nessas associações por um longo período de tempo. Assim, a filiação em associações religiosas não alterou muito entre as diferentes administrações do PT. Este núcleo é mais forte do que o resto de todas as associações tomadas em conjunto ${ }^{9}$. Contudo, quando consideramos o grupo de associações mais especializadas da sociedade civil, encarregadas de pressionar pela ampliação do acesso às políticas públicas, observamos um fenômeno diferente. Dentro deste grupo de associações, vemos uma diminuição no número de pessoas que aderem às associações voluntárias no ano de 2004 . Este decréscimo parece estar relacionado às mudanças na sociedade política e na parceria entre Estado e associações da sociedade civil nestas diferentes áreas de políticas públicas. Se tomarmos a área de

concepção normativa pré-concebida como os autores alegam. Ver, Dagnino (2002); Avritzer (2004); Dagnino, Olvera e Panfichi (2006).

7 Esta pesquisa teve como objetivo atualizar as formas de participação na cidade de São Paulo que passaram por fortes modificações entre o período final do autoritarismo e o começo do século. O principal achado da pesquisa é que o associativismo civil paulistano é altamente instável e se divide em dois grupos, um mais autônomo e um outro que responde aos incentivos à participação proposto por administrações de esquerda. A pesquisa mostrou também uma intensa variação da participação social por regiões da cidade de São Paulo. Assim, as regiões leste e oeste da cidade tem grande participação, ao passo que a região sul é muito pouco organizada.

8É importante ter em mente que a maioria das associações religiosas no Brasil são não-formais no sentido de que elas não se registram no cartório de registro de associações voluntárias. Isso também criou diferenças importantes entre as associações religiosas e de políticas públicas. Ver Avritzer (2004).

9É importante ter em mente que, devido a graves falhas metodológicas, Houtzager e Lavalle ignoram esta categoria. Para Houtzager, Lavalle e Charia, "laços com os sindicatos e as organizações religiosas não parecem afetar a propensão de atores da sociedade civil a participar (ver Houtzager, Lavalle e Charia, 2003, p. 8). A razão pela qual os autores chegaram a esta conclusão se deve a que eles usaram uma metodologia "bola de neve" para entrar num universo que é muito pluralista. Todos os seus pontos de partida foram relacionadas quer com os sindicatos ou com formas de ações patrocinadas por partidos. Não surpreende que eles não encontraram a categoria que é mais expressiva em termos de participação na cidade de São Paulo, as associações religiosas. Em um survey de uma amostra estatística da população com 2403 entrevistas, esta surgiu como a categoria mais importante. Ver Avritzer (2004). 
OPINIÃO PÚBLICA, Campinas, vol. 18, n², novembro, 2012, p. 383-398

saúde ou de habitação, que tem acolhido movimentos tradicionais na cidade de São Paulo (SADER, 1988; DoImo, 2004), vemos uma forte queda em 2004 em relação aos níveis anteriores de organização e participação. Não por acaso, estas foram áreas em que a administração anterior investiu fortemente na parceria entre Estado e sociedade civil e em que as ações conjuntas foram interrompidas entre os anos de 1993 e 2000, durante os governos conservadores de Paulo Maluf e Celso Pitta. Assim, o que temos em termos de organização da sociedade civil na cidade de São Paulo é, ao mesmo tempo, um núcleo de associações religiosas cuja participação é forte e varia muito pouco com as mudanças no sistema político e um segundo grupo de associações relacionadas às políticas públicas em que a participação varia de acordo com a disposição do Estado para incentivar ou impedir formas de colaboração com OSC. Nesse sentido, o argumento para uma completa interdependência entre a sociedade civil e o Estado parece não se sustentar, mesmo para a cidade de São Paulo, onde a propensão à participação mudou mais. Isto é particularmente importante uma vez que o caso de São Paulo é muito diferente dos de Porto Alegre e Belo Horizonte. Nestas cidades, o pertencimento a organizações da sociedade tende a ser mais constante devido a uma tendência de longo prazo para a colaboração conjunta entre sociedade civil e Estado nas administrações populares ligadas ao Partido dos Trabalhadores ${ }^{10}$. Neste caso, é mais difícil apresentar evidências das flutuações na participação da sociedade civil.

\section{Entre autonomia e dependência política: uma nova perspectiva sobre a sociedade civil brasileira}

A sociedade civil brasileira teve sua institucionalidade criada por dois processos, a reação dos setores populares ao processo antidemocrático de modernização do país que interferiu intensamente na sua vida cotidiana e um processo de democratização que fez das associações civis atores importantes no processo de aprofundamento democrático. As associações da sociedade civil mostram uma variedade de concepções de participação que resultam de ambos os processos. A sociedade civil brasileira tem um forte grupo de associações religiosas que participam de atividades de autoajuda e na organização dos pobres urbanos para reivindicar bens públicos. Este grupo tem uma forte presença na cidade de São Paulo, particularmente na zona leste, e é também forte em outras cidades como Recife e Belo Horizonte. Em Porto Alegre, este grupo é menos forte devido a maior influência dos setores de esquerda na formação da sociedade civil local (BAIOcCHI, 2005). Este grupo é mais ativo que o grupo de associações civis de políticas públicas no sentido em que se reúne mais vezes por semana, e é também mais voluntarista e mais preocupado com os problemas da comunidade (AVRITZER, 2004).

A sociedade civil brasileira também é formada por um grupo de associações fortemente ligadas ao Estado na implementação de políticas públicas. Este grupo tem ligações profundas com uma nova tradição de esquerda que surgiu durante a redemocratização. Seus laços mais fortes são com o Partido dos Trabalhadores e com as políticas participativas por ele implementadas no nível local, e sua participação varia em função da presença ou não do PT no poder. Quando o partido está no poder, este grupo de associações amplia-se em termos de membros, mostrando uma espécie de expansão e

\footnotetext{
10 Por motivos de ênfase conceitual, o problema da relação entre o associativismo civil e as administrações locais do PT não foi muito desenvolvido neste artigo, apesar de constituir pano de fundo do processo de mudança de perfil de muitas associações da sociedade civil. Diversos atores da sociedade civil estabeleceram relações com atores políticos, em especial aqueles que são membros do grupo que denominei de associativismo popular. Essa relação tem diminuído desde o começo do governo Lula e hoje se vê um setor forte do associativismo popular independente do PT.
} 
contração dinâmica que faz parte do comportamento da sociedade civil de São Paulo, devido à forte variação das orientações políticas no governo local desta cidade. O grupo religioso é mais estável, seus membros são mais ligados aos hábitos da população pobre e geograficamente está localizado fora do centro da cidade de São Paulo, e na maioria das periferias de grandes concentrações urbanas no país. 0 grupo de políticas públicas parece ser o que está mais fortemente comprometido com a democratização da ação do Estado. No entanto, ele está, predominantemente, localizado nas regiões centrais das grandes cidades. No caso de São Paulo, ele se radica na região oeste, uma das regiões mais afluentes da cidade ${ }^{11}$. Ele também interage mais com a sociedade civil tradicionalmente baseada na esquerda, tais como grupos feministas e ONGs.

É impossível compreender a sociedade civil brasileira sem analisar os dois grupos ao mesmo tempo. Associações que lidam com as políticas públicas são associações constituídas na maioria das vezes por atores de esquerda da classe média localizados em algumas cidades brasileiras, particularmente São Paulo. Reduzir a sociedade civil a este pequeno grupo de associações, tal como fazem Houtzager, Lavalle e Charia, equivale a ignorar o extenso processo de organização através do qual a população de baixa renda no Brasil têm se empenhado nos últimos 30 anos, em prol da reconstrução de um antigo argumento de esquerda sobre as ligações entre os partidos e os atores da sociedade civil. É melhor, heurística e politicamente, considerar a ampla gama de atores e objetivos que constituem a sociedade civil brasileira como uma instituição pluralista.

Os novos comportamentos políticos da sociedade civil brasileira ajudaram a modificar o padrão de associação no país. O Brasil fez uma transição difícil de um país com uma forte tradição de privatismo para um país com várias tradições políticas, entre elas a tradição de associações da sociedade civil independentes. O país também fez uma difícil transição do autoritarismo à democratização limitada e, após o processo constituinte, para uma democracia muito participativa. Associações voluntárias no Brasil, é verdade, interagem tanto com o Estado como com partidos políticos. Entretanto, a interação não tem mais o significado de um controle exercido pelo Estado, tal como ocorreu durante o período populista. Nenhum movimento expressa tão bem essa dupla face da interação entre o Estado e a sociedade civil como o Movimento dos Sem-Terra, na sua relação de aproximação e distanciamento do Estado. Importantes OSCs seguem a mesma lógica, tal como nós temos presenciado em relação aos negros e quilombolas. Só é possível entender essa lógica a partir da perspectiva de uma sociedade civil pluralista que se entende como independente dos partidos. É justamente essa independência que Ihe permitiu sobreviver à crise política que têm assolado o Brasil durante os últimos anos e manter a sua legitimidade entre amplos setores da sociedade.

\footnotetext{
${ }^{11}$ Devido à divisão da Arquidiocese de São Paulo pelo Papa João Paulo II durante o início dos anos oitenta e mais tarde a indicação do bispo conservador à nova arquidiocese na cidade, a região sul de São Paulo permaneceu como uma região com baixo número de associações e pessoas ligadas às associações. Ver Doimo (2004).
} 


\section{Referências Bibliográficas}

ABERS, R. N. e KeCK, M. "Muddy Waters: Decentralization, Coordination and Power Struggle in the Brazilian Water Management Reform". International Journal of Regional and Urban reform. Vol. 30, number 3, 2006.

Arato, A. "Civil Society vs. the State: Poland 1980-81", Telos, n 47, Spring, 1981.

Almond, G. and Verba, S. The civic culture: political attitudes and democracy in five nations. Princeton: Princeton University Press, 1963.

Alvarez, S. Engendering democracy in Brazil. Princeton: Princeton University Press, 1990.

Alvarez, S. E., Dagnino, E. Escobar, A. Cultures of Politics, Politics of Cultures: Re-visioning Latin American Social Movements, Boulder: Westview Press, 1998.

ARTURI, C. S. "O Debate Teórico sobre Mudança de Regime Político: o caso brasileiro". Revista de Sociologia e Política, $\mathrm{n}^{\circ} 17,2001$.

AuYero, J. Poor People's Politics: Peronist Survival Networks and the Legacy of Evit. Durham: Duke University Press, 2001.

AvritZer, L. Sociedade Civil e Democratização. Belo Horizonte: Del Rey, 1994.

. "Democratization and changes in the pattern of association in Brazil". Journal of Interamerican Studies and World Affairs, Fall, vol.42, n³, p. 59.76, 2000.

Democracy and the public space in Latin America. Princeton University Press, 2002.

(ed.). A participação em São Paulo. São Paulo: Editora UNESP, 2004.

“New public spheres in Brazil”. International Journal of Urban Regional Research, 2006.

Participatory Institutions in Democratic Brazil. Wilson Press/John Hopkins University Press, 2008.

Avritzer, L. Zander, N. A inovação democrática no Brasil. São Paulo: Cortez, 2003.

BAIOCCHI, G. Participation, Activism and Politics: The Porto Alegre Experiment and Deliberative Democratic Theory. Department of Sociology. University, 2005.

BobBio, N. Gramsci and the Concept of Civil Society. London: MacMillan, 1988.

Boschi, R. A arte da associação. Rio de Janeiro: Vértice, 1987.

CAldeira, T. São Paulo: city of walls. Berkeley: University of California Press, 2000.

Cohen, J. L. and Arato, A. Civil Society and Political Theory. Cambridge: MIT Press, 1992.

COHEN, J. L. and Rogers, J. Associations and democracy. London: Verso, 1995.

CoElHo, V. S. R. P. Conselhos de saúde enquanto instituições políticas: o que está faltando? In: Coelho, V. S. R. P.; Nobre, M. (eds.). Participação e Deliberação. São Paulo: 34Letras, p. 255·269, 2004.

Cornwall, A.; Coelho, V. S. R. P. Spaces for Change? The politics of citizen participation in new democratic arenas. $1^{\circ}$ ed. Londres: Zed Books, 2007

DAGNino, E. Os movimentos sociais e a emergência de uma nova noção de cidadania: In: DAgnino, E. (Ed.). Os anos 90 : Política e Sociedade no Brasil. São Paulo: Brasiliense, 1994.

Sociedade Civil e Espaços Públicos no Brasil. São Paulo: Paz e Terra, 2002.

Dagnino, E.; Olvera, A. J. and Panfichi, A. (eds.). A Disputa pela construção democrática na América Latina. S. Paulo: Paz e Terra, $501 \mathrm{pp}, 2006$.

Doımo, A. M. Pluralidade religiosa à brasileira, associativismo e movimentos sociais em São Paulo. In: AvRITZER, L. (Org). A participação em São Paulo. Unesp, 2004. 
AVRITZER, L. Sociedade civil e Estado no Brasil: da autonomia à interdependência política

ESCOREL, S. Reviravolta na saúde: origem e articulação do movimento sanitário. Rio de Janeiro: Editora FIOCRUZ, 1998.

Feinberg, R.; Waisman, C. and Zamosc, L. Civil society in Latin America. Palgrave, 2006.

FontanA, B. "Gramsci on politics and the state". Journal of Classical Sociology. Número 11, 2011.

Franco, M. S. C. Homens livres na ordem escravocrata. São Paulo: Ática Editores, 1974.

FREYRE, G. Masters and the slaves. New York Knopf. English translation, 1963 (1946).

The Mansions and the shanties. plantation relations and Mestizaje in American imaginaries. Edited by Alexandra Isfahani-Hammond. New York. Macmillan, 1959.

GAY, R. Popular organization and democracy in Rio de Janeiro. Philadelphia: Temple, 1994.

GOHN, M.G. Movimentos sociais e luta pela moradia. São Paulo: Edições Loyola, 1991.

HABERMAS, J. Between Facts and Norms. Cambridge: MIT Press, 1995.

HILAIRE, A. S. Segunda viagem do Rio de Janeiro a Minas Gerais. Belo Horizonte: Itatiaia, 1822.

Houtzager, P.; Lavalle, A. G.; Charia, A. "Who participates? Civil society and the new democratic politics in São Paulo, Brazil". Intitute of Development Studies. Working Paper, 2003.

Atores da sociedade civil e atores políticos: participação nas novas políticas democráticas em São Paulo. In: AvRITZER, L. A participação em São Paulo. São Paulo: Editora da UNESP, 2004.

KEANE, J. Civil society and the State. London: Verso, 1988a.

Civil society and democracy. London: Verso, 1988b.

Civil Society : Old Images, New Visions, Stanford: Stanford University Press, 1998.

Navarro, Z. Mobilização sem Emancipação - As Lutas Sociais dos Sem Terra no Brasil. In: Santos, B. S. (ed.). Produzir para Viver. Os Caminhos da Produção Não Capitalista. São Paulo: Civilização Brasileira, 2002.

O'DonneLL, G. AND SCHMitTer, P. Transitions from authoritarian rule. Baltimore: Johns Hopkins University Press, 1986.

OxHORN, P. Organizing Civil Society: the Popular Sectors and the Struggle for Democracy in Chile. University Park: Pennsylvania State University Press, 1995.

PereiRA, C. "A Política Pública como Caixa de Pandora: organização de interesses, processo decisório e efeitos perversos na Reforma Sanitária Brasileira - 1985-1989". Dados, vol.39, n. 3, 1996.

Putnam, R. Making democracy work. Princeton: Princeton University Press, 1993.

RIEDEL, M. Between Tradition and Revolution. Cambridge: Cambridge University Press, 1984.

Rodrigues Neto, E. Promessas e Limites da Constituição. Rio de Janeiro: Fiocruz, 2003.

REIS, E. "Desigualdade e Solidariedade: uma releitura do familismo amoral de Banfield". Revista Brasileira de Ciências Sociais, vol.10. n²9, 1995.

SADER, E. Quando Novos Personagens Entraram em Cena. São Paulo: Paz e Terra, 1988.

SANTOS, W. G. Cidadania e justiça: a política social na ordem brasileira. Rio de Janeiro: Ed. Campus, 1979.

Crise e Castigo. Rio de Janeiro: Vértice, 1987.

Razóes da Desordem. Rio de Janeiro: Rocco,1993.

SAULE JÚNIOR, N. “O Direito à cidade como paradigma da governança urbana democrática”. Instituto Polis, 2005.

Disponível em: <http://www. polis.org.br/artigo>. Acesso em: 08 maio 2006.

SHILS, E. The Virtue of Civility: Selected Essays on Liberalism, Tradition and Civil Society, Chicago: Liberty Fund., 1997. 
OPINIÃO PÚBLICA, Campinas, vol. 18, n², novembro, 2012, p. 383-398

SILvA, A. A. "A luta pelos direitos urbanos: novas representações de cidade e cidadania". Espaço \& Debates. São Paulo: v. 10, n. 30, p. $28 \cdot 41,1990$

Stepan, A. Democratizing Brazil. New York: Oxford University Press, 1989.

TAtAgiBA, L. Os Conselhos Gestores e a democratização das políticas públicas no Brasil. In: DAgnino, E. (ed.). Sociedade civil e espaços públicos no Brasil. São Paulo: Paz e Terra, 2002.

A institucionalização da participação: os conselhos municipais de políticas públicas na cidade de São Paulo. In: AvRITZer, L. A participação em São Paulo. São Paulo: Editora UNESP, p. 323-370, 2004.

Wampler, B. and Avritzer, L. Participatory publics: civil society and new institutions. New York: Comparative Politics, 2004.

WEFFORT, F. O populismo na política brasileira. São Paulo. Brasiliense, 1979.

Why Democracy. In: Stepan, A. Democratizing Brazil. New York: Oxford University Press, 1989.

WhitaKer, F. Iniciativa popular de lei: limites e alternativas. In: BenEVIDES, M. V.; VAnNUCHI, P. and KeRCHE, F. Reforma política e cidadania. São Paulo: Perseu Abramo, 2003.

Zauli, E. M. e Rodrigues, M. M. A. "Presidentes e Congresso Nacional no Processo Decisório da Política de Saúde no Brasil Democrático". Dados Revista de Ciências Sociais, Rio de Janeiro, v. 45, n. 3, p. 387-429, 2002.

Leonardo Avritzer · avritzer1@gmail.com

Submetido à publicação em setembro de 2011. Versão final aprovada em outubro de 2012. 